\title{
Stented elephant trunk procedure with left subclavian artery transposition for acute type B dissection with distal arch involvement
}

\author{
Jun-Ming Zhu, MD, ${ }^{\text {a }}$ Rui-Dong Qi, MD, ${ }^{\mathrm{a}}$ Lei Chen, MD, ${ }^{\mathrm{a}}$ Wei Liu, MD, ${ }^{\mathrm{a}}$ Cheng-Nan Li, MD, ${ }^{\mathrm{a}}$ \\ Zhan-Ming Fan, MD, and Li-Zhong Sun, MD
}

\begin{abstract}
Objective: Complete or partial supra-aortic debranching, after thoracic endovascular aortic repair, is appealing treatment for complicated acute type B dissection (ABAD) with aortic arch involvement (AAI) because of reduced surgical trauma. However, unsatisfactory outcomes have been reported. We retrospectively reviewed our experience of left subclavian artery (LSCA) transposition with stented elephant trunk (SET) implantation for complicated ABAD with distal AAI.
\end{abstract}

Methods: From April 2011 to December 2014, 19 patients (all men; mean age: 44 years) who had complicated ABAD and distal AAI underwent LSCA transposition with SET implantation via a median sternotomy under hypothermic cardiopulmonary bypass with selective cerebral perfusion. Preoperative renal dysfunction was observed in 3 patients, visceral ischemia in 2 patients, and lower-limb ischemia in 1 patient.

Results: No in-hospital deaths occurred. Seventeen patients required mechanical ventilation for $<24$ hours, and 2 cases for $<48$ hours. The mean time of mechanical ventilation and duration of stay in the intensive care unit was $18 \pm 6$ hours and $44 \pm 16$ hours, respectively. Ischemia of the viscera and lower limbs after surgery was ameliorated. Continuous renal replacement therapy was not required in 3 patients who had preoperative renal dysfunction. Complete thrombosis of the false lumen at the distal end of the SET was observed in 17 of 18 (94.4\%) patients during follow-up.

Conclusions: This method preserves autologous brachiocephalic vessels, excludes the false lumen, promotes thrombosis and remodeling of the distal aorta, and repairs proximal aortic lesions simultaneously. Satisfactory surgical outcomes and follow-up results were achieved using LSCA transposition with SET implantation. (J Thorac Cardiovasc Surg 2015;150:1160-5)

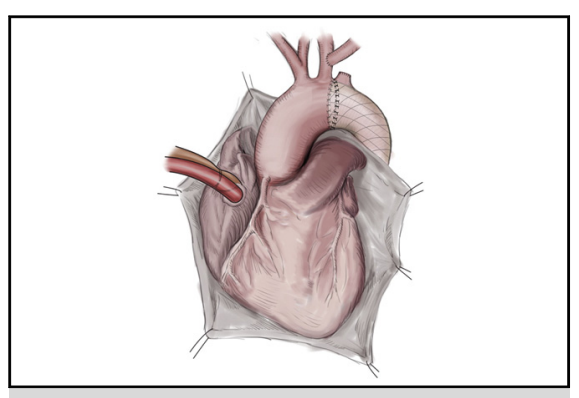

Left subclavian artery transposition, with stented elephant trunk implantation.

\section{Central Message}

This technique preserves autologous brachiocephalic vessels, excludes the false lumen, and permits repair of proximal aortic lesions.

\section{Perspective}

This method is advantageous because it does the following: preserves autologous brachiocephalic vessels with long-term patency; excludes the false lumen via the surgical stent graft; promotes thrombosis and remodeling of the false lumen; allows manipulation of proximal aortic lesions; and protects the myocardium. This technique may be suitable for treatment of acute type B dissection involving the distal aortic arch.

See Editorial Commentary page 1166.
Acute type B aortic dissection (ABAD) with aortic arch involvement (AAI) is not uncommon. Prevalence of this lesion has been reported to be $25.5 \%$ in patients who have $\mathrm{ABAD}$, according to the International Registry of

From the ${ }^{\mathrm{a} B e i j i n g}$ Aortic Disease Center, and ${ }^{\mathrm{b}}$ Department of Radiology, Beijing Institute of Heart, Lung and Blood Vessel Diseases \& Beijing Anzhen Hospital, Capital Medical University, Beijing, China.

This study was supported by grants from The Capital Health Research and Development of Special (2011-2006-05).

Received for publication April 3, 2015; revisions received July 17, 2015; accepted for publication July 24, 2015; available ahead of print Sept 3, 2015.

Address for reprints: Li-Zhong Sun, MD, Beijing Aortic Disease Center, Beijing Anzhen Hospital, Capital Medical University, 2 Anzhen Rd, Beijing 100029, People's Republic of China (E-mail: lizhongsun@outlook.com).

0022-5223/\$36.00

Copyright (c) 2015 by The American Association for Thoracic Surgery

http://dx.doi.org/10.1016/j.jtcvs.2015.07.089
Acute Aortic Dissection. ${ }^{1}$ Compared with open surgery, supra-aortic debranching after thoracic endovascular aortic repair (TEVAR) is an appealing treatment for complicated ABAD with AAI, because less surgical trauma is involved. However, unsatisfactory outcomes, with high morbidity and mortality, have been reported. ${ }^{2-4}$

Management of complicated ABAD with AAI is controversial. In previous reports from Sun and colleagues, ${ }^{5}$ and Zhao and colleagues, ${ }^{6}$ total replacement of the aortic arch with stented elephant trunk (SET) implantation was undertaken for type B dissection with AAI, and satisfactory results were achieved. Here, we report our experience with 19 consecutive patients who underwent transposition of the left subclavian artery (LSCA) with SET implantation for complicated ABAD with distal AAI. 


\section{Abbreviations and Acronyms}

$\mathrm{AAI}=$ aortic arch involvement

$\mathrm{ABAD}=$ acute type $\mathrm{B}$ dissection

LCCA $=$ left common carotid artery

LSCA = left subclavian artery

SET $=$ stented elephant trunk

TEVAR $=$ thoracic endovascular aortic repair

\section{METHODS}

\section{Patients}

The study protocol was approved by the Ethics Review Board of Capital Medical University (Beijing, People's Republic of China). Between April 2011 and December 2014 in our center, a total of 19 patients (all men) with complicated ABAD and distal AAI (Figure 1) underwent transposition of the LSCA, with SET implantation, via a median sternotomy under hypothermic cardiopulmonary bypass with antegrade selective cerebral perfusion The mean age was $44 \pm 11$ years (range: 27-62 years). Surgery was undertaken $<2$ weeks after the onset of pain. Patients with ABAD with distal AAI were confirmed preoperatively using computed tomography and echocardiography.

An isolated left vertebral artery was observed in 2 patients. Renal dysfunction was noted in 3 cases, visceral ischemia in 2, and lower-limb ischemia in 1 patient. Thirteen patients had a history of hypertension. Preoperative complications were common (Table 1).

Among the 19 patients with complicated ABAD, the tear site was located at the following locations: the distal aortic arch (4 patients); the proximal descending thoracic aorta adjacent to the origin of the LSCA (12 patients); and the proximal descending thoracic aorta distal to the origin of the LSCA (3 patients). All patients had distal AAI. Aortic dissection involved the thoracoabdominal aorta in all cases, and extended to the iliac artery in 14 patients.

\section{Surgical Procedure}

A median sternotomy was done in all patients. Brachiocephalic vessels and the transverse arch were dissected and freed from their surrounding attachments. The key step in an end-to-side anastomosis between the 2 vessels was mobilization of the LSCA and left common carotid artery (LCCA). The LSCA and LCCA were exposed as much as possible. To mobilize fully, the left sternocleidomastoid muscle and other cervical muscle groups could be partially transected. After the LCCA was mobilized fully, the LSCA was separated behind the left side of the LCCA. Extent of mobilization ranged from the transverse arch to the origin of the left vertebral artery. During mobilization, injury to the thoracic duct should be avoided.

Ligation of the thoracic duct was undertaken if necessary. Cardiopulmonary bypass was established using the arterial cannulation of the right axillary artery, and venous cannulation of the right atrium. Cannulation of the right axillary artery was used for cardiopulmonary bypass and selective cerebral perfusion. During cooling, a proximal aortic procedure was done if necessary.

Brachiocephalic vessels were clamped after the nasopharyngeal temperature reached $25^{\circ} \mathrm{C}$. Circulatory arrest was instituted, and the brain perfused at approximately 5 to $10 \mathrm{ml}$ per $\mathrm{kg}$ per minute using antegrade selective cerebral perfusion. Our methods for type B dissection using SET have been described in detail. ${ }^{7}$ After an incision in the aortic arch was carried out (Figure 2, A), a 10 to $15 \mathrm{~cm}$ self-expandable stented graft (Cronus; Shanghai MicroPort Medical, Shanghai, China) was delivered and released via the incision in the aortic arch (Figure 2,B).

After the surgical graft was implanted in the correct location of the true lumen of the distal aorta in a bound, compressed state, the graft was fixed in the true lumen of the distal aorta by the self-expanding stent, to make the true lumen expandable (Figure 2, $C$ ). The suture was run within the aortic arch, and the distal aorta containing the proximal stent-free sewing edge was sutured to the normal aortic arch wall between the LSCA and the LCCA origin, using a continuous circumferential suture line (Figure 2, $D)$. After suturing, cardiopulmonary bypass was gradually returned to normal flow, and rewarming was started. Next, the LSCA was clamped and divided transversely 0.5 to $1.0 \mathrm{~cm}$ distal to its origin (Figure 2,E). The proximal stump of the LSCA was sutured, using a continuous running suture of 5/0 polypropylene (Figure 2,F).

The LCCA was clamped and opened longitudinally. The distal portion of the LSCA was anastomosed to the LCCA with an end-to-side style using 6/0 Prolene (polypropylene; Ethicon, Inc, Somerville, NJ; Figure 2, F). In patients with type $\mathrm{B}$ dissection with the isolated left vertebral artery, a similar procedure was done between that artery and the LCCA.

Mean cardiopulmonary bypass time, aortic crossclamp time, and antegrade selective cerebral perfusion time was (in minutes): $108 \pm 22$, $46 \pm 19$, and $22 \pm 4$, respectively. Concomitant isolated left vertebral artery-LCCA transposition was undertaken in 2 patients who had complicated ABAD with the isolated left vertebral artery, and aortic valve replacement with coronary artery bypass grafting in 1 patient.

\section{RESULTS}

\section{Morbidity and Mortality}

No in-hospital deaths occurred. Seventeen patients required mechanical ventilation for $<24$ hours, and 2 cases for $<48$ hours. The mean time of mechanical ventilation and duration of stay in the intensive care unit (in hours) was $18 \pm 6$ (range: $11-31$ ) and $44 \pm 16$ (range: 20-91), respectively. After SET implantation, the preoperative ischemia of visceral organs and lower limbs, and renal dysfunction were greatly ameliorated. Continuous renal replacement therapy was not required in 3 patients, who had preoperative renal dysfunction. Neurologic deficit and injury to the spinal cord were not observed. All patients survived and were discharged from the hospital.

\section{Follow-up}

Only 1 patient was lost to follow-up. No deaths occurred during a mean follow-up period of $17 \pm 11$ months. Injury to the spinal cord, and visceral malperfusion, was not observed after surgery. One patient underwent thoracoabdominal aortic replacement 5 months after surgery, and recovered uneventfully after hospital discharge. Patients had a normal life during follow-up. Differences after TEVAR in revascularization of the LSCA and/or the LCCA, and in partial or complete aortic arch debranching, are listed in Table 2.

Postoperative computed tomography revealed the good patency of the anastomotic site between the LSCA and LCCA (Figure 3). A subtle proximal endoleak, caused by a stitch length that was too wide, was observed in 1 patient after surgery. After summing up the experiences of this case, no proximal endoleaks occurred since then. The proximal endoleak disappeared 2 years after surgery.

Thrombus formation in the false lumen around the SET was observed in 17 of $18(94.4 \%)$ patients who had 


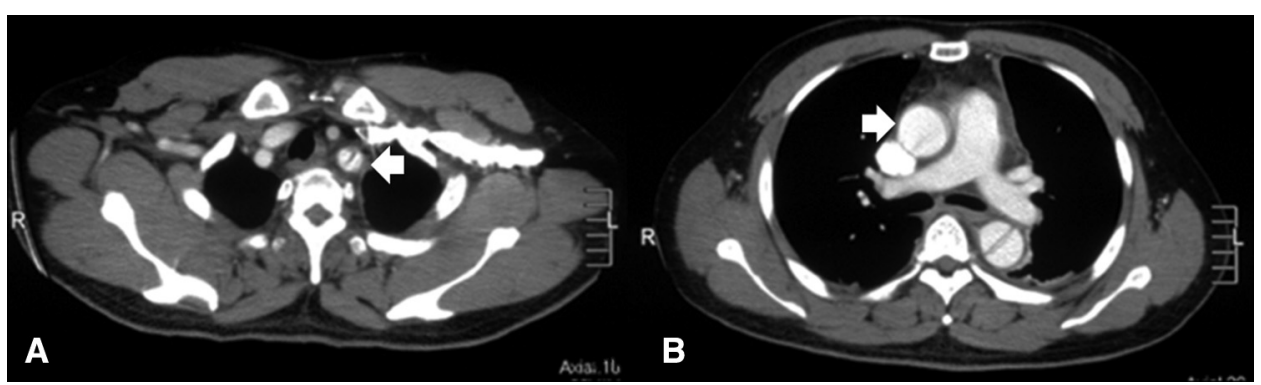

FIGURE 1. Computed tomography of a patient with acute type B dissection with distal aortic arch involvement before surgery. The left subclavian artery was involved via type B dissection (Figure 1,A). The ascending aorta was normal (Figure 1,B).

complicated ABAD with distal AAI, either extended to the diaphragmatic level (16 of 18 [88.8\%] patients), at the diaphragmatic level (10 of 18 [55.6\%] patients), or at the celiac trunk level (6 of 18 [33.3\%] patients).

\section{DISCUSSION}

In patients with $\mathrm{ABAD}$ with $\mathrm{AAI}$, simultaneous repair of aortic-arch lesions and descending aortic dissection via a median sternotomy or lateral thoracotomy is very challenging. Several methods, such as conventional elephant trunk, hybrid approach, ${ }^{2}$ and SET, ${ }^{5,6,11}$ were introduced to manage this troublesome problem. Application of the conventional elephant trunk was limited because of the characteristics of the soft prosthetic graft ${ }^{12}$; complications associated with the graft $^{13}$; and cumulative risk between the first and second stage of the procedure. ${ }^{14,15}$
With regard to hybrid procedures, complete or partial debranching of the supra-aortic arch vessels has been undertaken to create an adequate proximal landing zone for TEVAR in patients who have ABAD and AAI. ${ }^{4}$ Owing to a minimally invasive approach, favorable results were achieved for complicated acute type B dissection using TEVAR, in a study by the International Registry of Acute Aortic Dissection, ${ }^{16}$ and other studies, ${ }^{17,18}$ and for complicated type B dissection using partial aortic arch debranching after TEVAR. ${ }^{8-10}$ However, unsatisfactory results have been reported $^{19,20}$ with type B dissection using TEVAR and on supra-aortic debranching after TEVAR. ${ }^{2-4}$ Postoperative complications related to hybrid repair of the aortic arch (eg, retrograde type A dissection, stroke, endoleak) are very common, and in-hospital mortality is high. ${ }^{2-4}$ Hybrid repair of the aortic arch, for aortic dissection involving the

TABLE 1. Clinical profiles for acute type B dissection with involvement of the distal aortic arch

\begin{tabular}{|c|c|c|c|c|c|c|}
\hline $\begin{array}{c}\text { Patient } \\
\text { no. } \\
\end{array}$ & Age (y) & Gender & Symptoms and findings & Location of primary tear & $\begin{array}{c}\text { Concomitant } \\
\text { procedure }\end{array}$ & Outcome \\
\hline 1 & 59 & M & $\begin{array}{l}\text { HT/CAD/DM/renal dysfuction/renal ischemia/pleural } \\
\text { effusion }\end{array}$ & Distal aortic arch & & Alive \\
\hline 2 & 59 & M & Uncontrolled HT/ILVA/persistent pain & Adjacent to the LSCA origin & ILVA-LCCA & Alive \\
\hline 3 & 29 & M & HT/lower-limb ischemia/pleural effusion & Adjacent to the LSCA origin & & Alive \\
\hline 4 & 36 & M & HT/renal dysfuction/pleural effusion & Adjacent to the LSCA origin & & Alive \\
\hline 5 & 53 & M & $\mathrm{HT} /$ visceral ischemia/pleural effusion & Adjacent to the LSCA origin & $\begin{array}{l}\text { ILVA-LCCA } \\
\text { transposition }\end{array}$ & Alive \\
\hline 6 & 55 & M & $\mathrm{HT} / \mathrm{renal}$ ischemia & Distal to the aortic arch & & Alive \\
\hline 7 & 42 & M & HT/pleural effusion/persistent pain & Adjacent to the LSCA origin & & Alive \\
\hline 8 & 35 & M & Pleural effusion/persistent pain & Adjacent to the LSCA origin & & Alive \\
\hline 9 & 43 & M & HT/partial renal infarction/pleural effusion & Distal aortic arch & & Alive \\
\hline 10 & 44 & M & HT/renal dysfuction/renal ischemia & Adjacent to the LSCA origin & & Alive \\
\hline 11 & 30 & M & Visceral ischemia/renal ischemia & Adjacent to the LSCA origin & & $\begin{array}{l}\text { Lost to } \\
\text { follow-up }\end{array}$ \\
\hline 12 & 42 & M & Uncontrolled HT & Adjacent to the LSCA origin & & Alive \\
\hline 13 & 27 & M & Gastrointestinal hemorrhage & Adjacent to the LSCA origin & & TAAR \\
\hline 14 & 62 & M & $\mathrm{HT} / \mathrm{CAD} / \mathrm{AR} / \mathrm{renal}$ ischemia & Adjacent to the LSCA origin & AVR/CABG & Alive \\
\hline 15 & 48 & M & DM/pleural effusion/uncontrolled HT & Distal to the aortic arch & & Alive \\
\hline 16 & 33 & M & Uncontrolled HT & Distal aortic arch & & Alive \\
\hline 17 & 36 & M & Renal ischemia & Adjacent to the LSCA origin & & Alive \\
\hline 18 & 43 & M & Uncontrolled HT & Distal aortic arch & & Alive \\
\hline 19 & 48 & M & Pleural effusion/persistent pain & Distal to the aortic arch & & Alive \\
\hline
\end{tabular}

$M$, Male; $H T$, hypertension; $C A D$, coronary artery disease; $D M$, diabetes mellitus; ILVA, isolated left vertebral artery; $L S C A$, left subclavian artery; $L C C A$, left common carotid artery; $T A A R$, thoracoabdominal aortic replacement; $A R$, aortic regurgitation; $A V R$, aortic valve replacement; $C A B G$, coronary artery bypass grafting. 

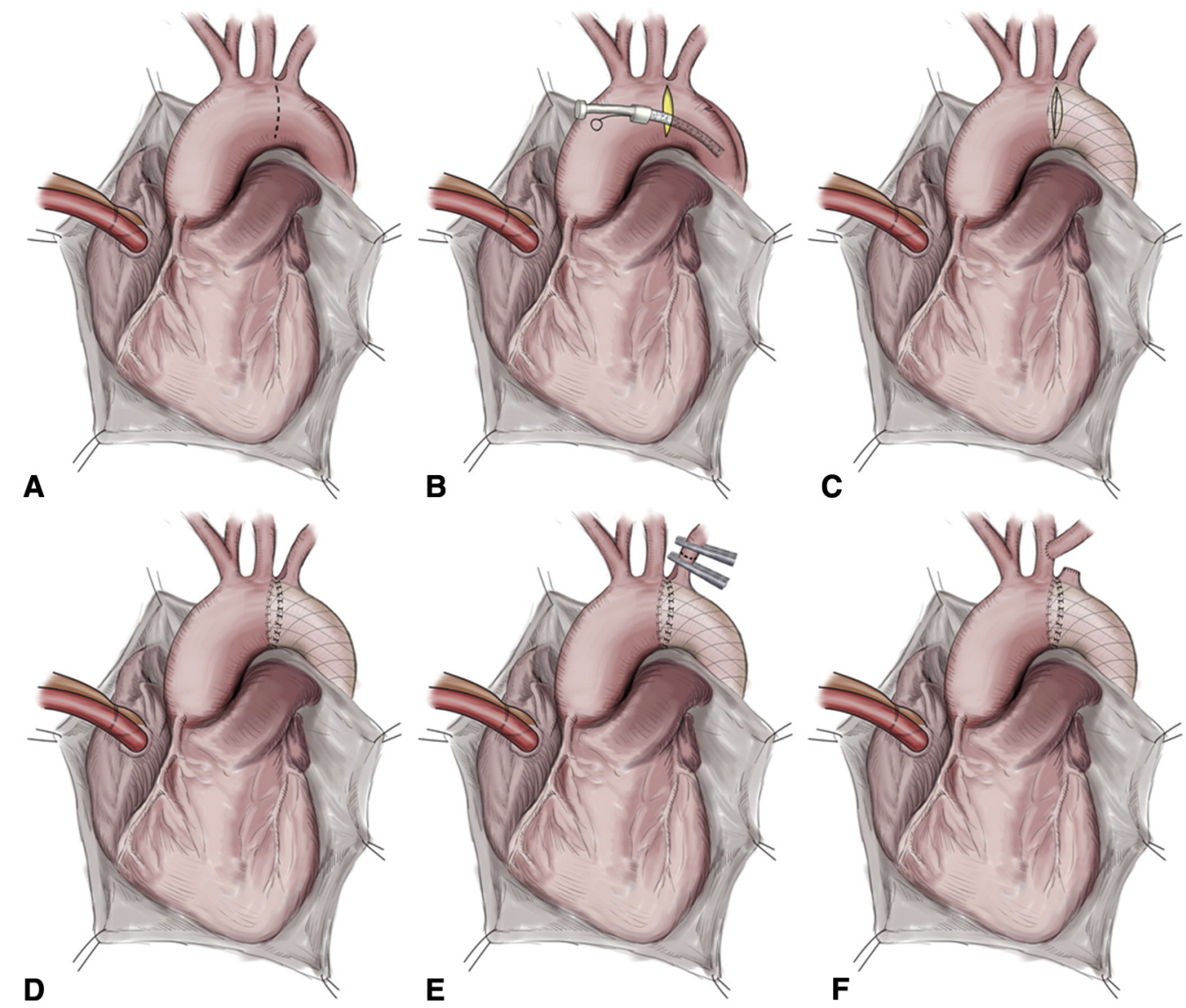

FIGURE 2. The stented elephant trunk procedure, with transposition of the left subclavian artery to the left common carotid artery. A, An incision in the aortic arch was carried out. B, A stented elephant trunk was implanted into the distal aorta. C, The self-expanded surgical-stent was fixed in the distal aorta. D, Sewing of the surgical-stent to the normal aortic arch was carried out. E, The LSCA was clamped and divided transversely. F, Transposition of the left subclavian artery to the left common carotid artery.

aortic arch, has been suggested to be a risky procedure, especially in patients who have acute dissection. ${ }^{4}$

Owing to the superiority of a combination of surgical and interventional approaches, ${ }^{21}$ satisfactory outcomes have been obtained ${ }^{5,6}$ in patients who have ABAD with AAI, using the Cronus stent graft. ${ }^{5,6}$ In our center, as reported, ${ }^{5,6}$ to preserve the normal aortic wall and reduce application of the prosthetic graft, the LSCA was transposed to the LCCA, with exclusion of lesions distal to the LCCA origin by a SET, in patients with complicated ABAD and distal AAI beyond the LCCA origin. Indications for this procedure for ABAD with distal AAI were: (1) distal AAI was limited distal to the origin of the LCCA; (2) no involvement of, aneurysm formation, or occlusion of the innominate artery or LCCA; (3) resected distal portion of the LSCA was normal, irrespective of whether the proximal stump of the LSCA was involved via aortic dissection. If the LCCA origin was involved via $\mathrm{ABAD}$, total replacement of the aortic arch, combined with implantation of a SET, was undertaken. ${ }^{5,6}$
Transposition of the LSCA with implantation of a SET produced 5 main advantages. First, instead of a prosthetic graft, which can lead to complications from infection, and other potential adverse consequences, ${ }^{22}$ the autologous LSCA was preserved in its entirety. Occlusion and/or stenosis of the bypass graft was reported recently. ${ }^{2,4}$ Stenosis, obstruction, and clots of the prosthetic graft were avoided, and this method yielded long-term patency. Second, after transposition of the LSCA, the false lumen distal to the LCCA origin was excluded completely, using a SET, and this strategy promoted remodeling of the false lumen of the distal aorta.

Third, facilitation of late distal aortic intervention was made easier and safer, owing to the surgical graft having a sewing edge or acting as a landing zone for TEVAR. ${ }^{23}$ Fourth, the distal aortic arch incorporating the surgical graft was fixed firmly to the normal aortic wall using a suture line, which avoided proximal endoleaks and development of a retrograde type A dissection. The final advantage was that concomitant proximal aortic lesions and/or cardiac disease were repaired in 1 stage. 
TABLE 2. Studies on hybrid techniques for type B aortic dissection

\begin{tabular}{|c|c|c|c|c|c|c|c|c|}
\hline \multirow[b]{2}{*}{ Study } & \multirow{2}{*}{$\begin{array}{c}\text { In-hospital } \\
\text { mortality }\end{array}$} & \multicolumn{5}{|c|}{ In-hospital morbidity } & \multicolumn{2}{|c|}{ Follow-up } \\
\hline & & Stroke & SCI & Endoleak & R-TAAD & Total & Endoleak & Reintervention \\
\hline \multicolumn{9}{|l|}{$\begin{array}{l}\text { TEVAR + only LSCA } \\
\text { revascularization }\end{array}$} \\
\hline Kefeng $^{8}(\mathrm{n}=15)$ & $0(0)$ & $0(0)$ & $0(0)$ & $0(0)$ & $0(0)$ & $6.7(1)$ & $7.7(1)^{*}$ & $6.7(1)$ \\
\hline Patterson $^{9}(\mathrm{n}=49)$ & NR & $6.1(3)$ & $2.0(1)$ & NR & NR & NR & NR & NR \\
\hline \multicolumn{9}{|c|}{$\begin{array}{l}\text { TEVAR + LCCA or and LSCA } \\
\text { revascularization }\end{array}$} \\
\hline Cochennec $^{4}(\mathrm{n}=10)$ & $40(4)$ & $10(1)$ & $0(0)$ & $10(1)$ & $30(3)$ & $80(8)$ & $10(1)$ & $20(2)$ \\
\hline \multicolumn{9}{|c|}{$\begin{array}{l}\text { TEVAR + partial aortic arch } \\
\text { de-branching } \dagger\end{array}$} \\
\hline Geisbusch $^{3}(\mathrm{n}=32)$ & $15.6(5)$ & $6.3(2)$ & $6.3(2)$ & $15.6(5)$ & $3.1(1)$ & $50(16)$ & NR & $6.3(2)$ \\
\hline $\mathrm{Lu}^{10}(\mathrm{n}=22)$ & $9.1(2)$ & $4.5(1)$ & $0(0)$ & $4.5(1)$ & $0(0)$ & $9.1(2)$ & $0(0)$ & $4.5(1)$ \\
\hline $\begin{array}{l}\text { TEVAR }+ \text { aortic arch de } \\
\text { Bunger }^{2}(\mathrm{n}=45)\end{array}$ & $11.1(5)$ & $8.8(4)$ & $2.2(1)$ & $27(12)$ & $2.2(1)$ & $66.7(30)$ & $43(13) \S$ & $18(8)$ \\
\hline \multicolumn{9}{|c|}{ SET + LSCA-LCCA transposition } \\
\hline Zhu $(\mathrm{n}=19) \|$ & $0(0)$ & $0(0)$ & $0(0)$ & $5.3(1)$ & $0(0)$ & $5.3(1)$ & $0(0) \dagger$ & $5.3(1)$ \\
\hline
\end{tabular}

No in-hospital deaths occurred, nor did severe complications in our study cohort. During follow-up, thrombosis of the false lumen was observed in most patients. To facilitate late distal aortic intervention, ${ }^{24}$ late thoracoabdominal aortic replacement was done easily in 1 patient, using this method in the present study. Satisfactory surgical outcomes and follow-up results were obtained using this method. With a mean age of $44 \pm 11$ years, patients tended to be younger and survive longer after successful surgery.

Late complications related to TEVAR are much more common than those relating to open aortic surgery. ${ }^{25}$ Risk-adjusted and propensity-matched comparisons showed that long-term survival is better with open surgery than with TEVAR. ${ }^{26}$ These results suggest that TEVAR should be carried out in higher-risk patients. ${ }^{26}$ Given the need to balance short- and long-term results, this relatively aggressive approach might be justified for this group. The SET procedure, with varying degrees of reconstruction of vessels in the aortic arch, is an alternative to the hybrid technique for $\mathrm{ABAD}$ involving the distal aortic arch.

Some limitations of the study should be taken into consideration. The number of patients in this study is small, implying some weakness of the surgical statistical results. Second, our study lacks a control group of patients undergoing the hybrid technique (partial supra-aortic debranching after TEVAR). In our center, the hybrid technique is performed for patients who cannot tolerate open surgery.

Using a control group creates selection bias, and significant differences can be found in important demographic and clinical characteristics between the hybrid technique and

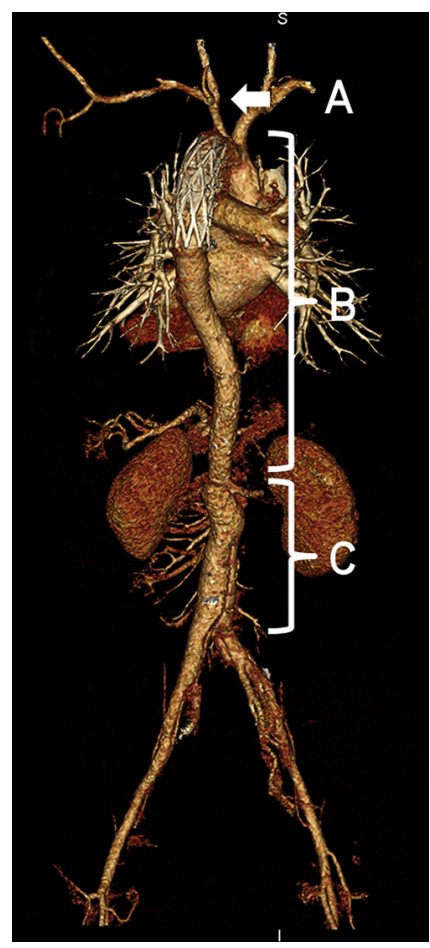

FIGURE 3. Three-dimensional reconstruction of a computed tomography scan of acute type B dissection using a stented elephant trunk procedure with transposition of the left subclavian artery to the left common carotid artery 1 year after surgery. Good patency of the anastomotic site between the (A) left common carotid artery and the left subclavian artery; (B) descending thoracic aorta and upper abdominal aorta, returned to normal after remodeling; and $(\mathrm{C})$ false lumen in the abdominal aorta below the upper abdominal aorta. 
the SET procedure. Third, younger patients survive longer overall than do older patients, after successful surgery. The SET procedure benefited those patients who had type A dissection, with respect to early and late results, because of its good intraoperative handling and good postoperative recovery. ${ }^{21}$ A randomized controlled trial to solve this problem would likely be unethical. The long-term durability of this procedure needs to be confirmed.

\section{CONCLUSIONS}

The method described here illustrates the advantages of a combination of surgical and interventional approaches. It preserves the autologous LSCA with long-term patency, excludes the false lumen distal to the LCCA origin, promotes thrombosis and remodeling of the false lumen of the distal aorta, enables manipulation of proximal aortic lesions, and protects the myocardium. Satisfactory surgical results and follow-up outcomes were obtained using transposition of the LSCA with the SET procedure. The encouraging outcomes of the present study favor this method for ABAD with distal AAI. However, the surgical results were preliminary, and long-term follow-up is required.

\section{Conflict of Interest Statement}

Authors have nothing to disclose with regard to commercial support.

\section{References}

1. Tsai TT, Isselbacher EM, Trimarchi S, Bossone E, Pape L, Januzzi JL, et al. Acute type B aortic dissection: Does aortic arch involvement affect management and outcomes? Insights from the International Registry of Acute Aortic Dissection (IRAD). Circulation. 2007;116(11 Suppl):I150-6.

2. Bunger CM, Kische S, Liebold A, Leissner M, Glass A, Schareck W, et al. Hybrid aortic arch repair for complicated type B aortic dissection. J Vasc Surg. 2013;58:1490-6.

3. Geisbusch P, Kotelis D, Muller-Eschner M, Hyhlik-Durr A, Bockler D. Complications after aortic arch hybrid repair. J Vasc Surg. 2011;53:935-41.

4. Cochennec F, Tresson P, Cross J, Desgranges P, Allaire E, Becquemin JP. Hybrid repair of aortic arch dissections. J Vasc Surg. 2013;57:1560-7.

5. Sun L, Zhao X, Chang Q, Zhu J, Liu Y, Yu C, et al. Repair of chronic type B dissection with aortic arch involvement using a stented elephant trunk procedure. Ann Thorac Surg. 2010;90:95-100.

6. Zhao HP, Zhu JM, Ma WG, Zheng J, Liu YM, Sun LZ. Total arch replacement with stented elephant trunk technique for acute type B aortic dissection involving the aortic arch. Ann Thorac Surg. 2012;93:1517-22.

7. Zhu J, Cheng L, Liu Y, Zheng J, Qiao Z, Li C, et al. One-stage repair for Stanford type B aortic dissection concomitant with cardiac diseases: open stented elephant trunk technique combined with cardiac operation. Thorac Cardiovasc Surg. 2012;60:11-6.

8. Kefeng Z, Xudong P, Yongmin L, Junming Z, Lianjun H, Jian Z, et al. Hybrid operation for type B aortic dissection involving distal aortic arch. J Card Surg. 2014;29:359-63.

9. Patterson BO, Holt PJ, Nienaber C, Fairman RM, Heijmen RH, Thompson MM. Management of the left subclavian artery and neurologic complications after thoracic endovascular aortic repair. J Vasc Surg. 2014;60:1491-7.
10. Lu Q, Jing Z, Zhao Z, Bao J, Feng X, Feng R, et al. Endovascular stent graft repair of aortic dissection type B extending to the aortic arch. Eur J Vasc Endovasc Surg. 2011;42:456-63.

11. Weiss G, Tsagakis K, Jakob H, Di Bartolomeo R, Pacini D, Barberio G, et al. The frozen elephant trunk technique for the treatment of complicated type B aortic dissection with involvement of the aortic arch: multicentre early experience. Eur J Cardiothorac Surg. 2015;47:106-14.

12. Kieffer E, Koskas F, Godet G, Bertrand M, Bahnini A, Benhamou AC, et al Treatment of aortic arch dissection using the elephant trunk technique. Ann Vasc Surg. 2000;14:612-9.

13. Crawford ES, Coselli JS, Svensson LG, Safi HJ, Hess KR. Diffuse aneurysma disease (chronic aortic dissection, Marfan, and mega aorta syndromes) and multiple aneurysm. Treatment by subtotal and total aortic replacement emphasizing the elephant trunk operation. Ann Surg. 1990;211:521-37.

14. LeMaire SA, Carter SA, Coselli JS. The elephant trunk technique for staged repair of complex aneurysms of the entire thoracic aorta. Ann Thorac Surg. 2006;81:1561-9.

15. Safi HJ, Miller CC III, Estrera AL, Huynh TT, Rubenstein FS, Subramaniam MH, et al. Staged repair of extensive aortic aneurysms: morbidity and mortality in the elephant trunk technique. Circulation. 2001;104:2938-42.

16. Fattori R, Montgomery D, Lovato L, Kische S, Di Eusanio M, Ince H, et al. Survival after endovascular therapy in patients with type $\mathrm{B}$ aortic dissection: a report from the International Registry of Acute Aortic Dissection (IRAD). JACC Cardiovasc Interv. 2013;6:876-82.

17. Steuer J, Eriksson MO, Nyman R, Björck M, Wanhainen A. Early and long term outcome after thoracic endovascular aortic repair (TEVAR) for acute complicated type B aortic dissection. Eur J Vasc Endovasc Surg. 2011;41: 318-23.

18. Qin YL, Deng G, Li TX, Wang W, Teng GJ. Treatment of acute type-B aortic dissection: thoracic endovascular aortic repair or medical management alone? JACC Cardiovasc Interv. 2013;6:185-91.

19. Böckler D, Hyhlik-Dürr A, Hakimi M, Weber TF, Geisbüsch P. Type B aortic dissections: treating the many to benefit the few? J Endovasc Ther. 2009;16(Suppl 1):I80-90.

20. Alves CM, da Fonseca JH, de Souza JA, Kim HC, Esher G, Buffolo E. Endovascular treatment of type B aortic dissection: the challenge of late success. Ann Thorac Surg. 2009;87:1360-5.

21. Sun L, Qi R, Zhu J, Liu Y, Zheng J. Total arch replacement combined with stented elephant trunk implantation: a new "standard" therapy for type A dissection involving repair of the aortic arch? Circulation. 2011;123:971-8.

22. Cinà CS, Safar HA, Laganà A, Arena G, Clase CM. Subclavian carotid transposition and bypass grafting: consecutive cohort study and systematic review. $J$ Vasc Surg. 2002;35:422-9.

23. Uchida N, Kodama H, Katayama K, Takasaki T, Katayama A, Takahashi S, et al Endovascular aortic repair as second-stage surgery after hybrid open arch repair by the frozen elephant trunk technique for extended thoracic aneurysm. Ann Thorac Cardiovasc Surg. 2013;19:257-61.

24. Pichlmaier MA, Teebken OE, Khaladj N, Weidemann J, Galanski M, Haverich A. Distal aortic surgery following arch replacement with a frozen elephant trunk. Eur J Cardiothorac Surg. 2008;34:600-4.

25. Svensson LG, Kouchoukos NT, Miller DC, Bavaria JE, Coselli JS, Curi MA et al. Expert consensus document on the treatment of descending thoracic aortic disease using endovascular stent-grafts. Ann Thorac Surg. 2008;85(1 Suppl): S1-41.

26. Goodney PP, Travis L, Lucas FL, Fillinger MF, Goodman DC, Cronenwett JL, et al. Survival after open versus endovascular thoracic aortic aneurysm repair in an observational study of the Medicare population. Circulation. 2011;124: 2661-9.

Key Words: left subclavian artery transposition, stented elephant trunk procedure, acute type B dissection, distal aortic arch involvement 